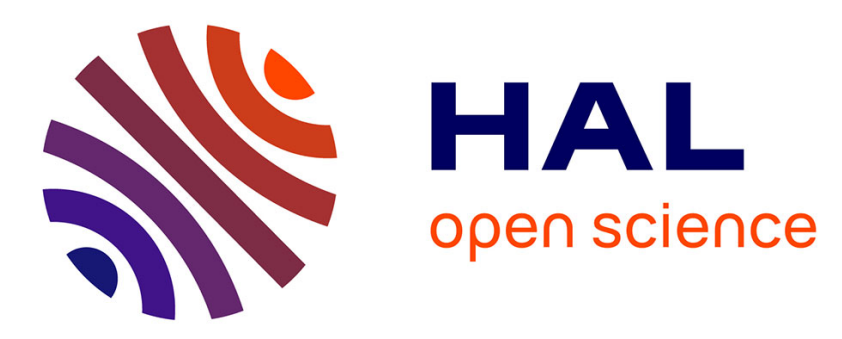

\title{
Plug-in Electric Vehicle Collaborative Charging for Current Unbalance Minimization: Ant System Optimization Application
}

Julian Alberto Fernandez Orjuela, Seddik Bacha, Delphine Riu, Ahmad Hably

\section{To cite this version:}

Julian Alberto Fernandez Orjuela, Seddik Bacha, Delphine Riu, Ahmad Hably. Plug-in Electric Vehicle Collaborative Charging for Current Unbalance Minimization: Ant System Optimization Application. ICIT 2015 - IEEE International Conference on Industrial Technology, Mar 2015, Séville, Spain. 10.1109/ICIT.2015.7125494 . hal-01134614

\author{
HAL Id: hal-01134614 \\ https://hal.science/hal-01134614
}

Submitted on 24 Mar 2015

HAL is a multi-disciplinary open access archive for the deposit and dissemination of scientific research documents, whether they are published or not. The documents may come from teaching and research institutions in France or abroad, or from public or private research centers.
L'archive ouverte pluridisciplinaire HAL, est destinée au dépôt et à la diffusion de documents scientifiques de niveau recherche, publiés ou non, émanant des établissements d'enseignement et de recherche français ou étrangers, des laboratoires publics ou privés. 


\section{Plug-in Electric Vehicle Collaborative Charging for Current Unbalance Minimization: Ant System Optimization Application}

\author{
Julian A. Fernandez \\ Gipsa-lab
}

\author{
Seddik Bacha and Delphine Riu \\ G2elab, Grenoble, France \\ Email: seddik.bacha@g2elab.grenoble-inp.fr \\ delphine.riu@g2elab.grenoble-inp.fr
}

\author{
Ahmad Hably \\ Gipsa-lab, Grenoble-INP, France \\ IEEE member \\ Email.ahmad.hably@grenoble-inp.fr
}

\begin{abstract}
Plug-in electric vehicles (PEVs) are one of the solutions to reduce transportation dependency on oil. Nevertheless, uncoordinated charging in distribution low voltage (LV) networks can lead to local grid problems such as current unbalance and consequently voltage unbalance. In this paper, a combinatorial method based on Ant System (AS) optimization is proposed in order to minimize the current unbalance factor (CUF) by controlling the connection and disconnection of PEVs. The CUF is generated by PHEVs and neighboring residential loads. In addition a simulation environment is implemented to validate the performance of the AS method by benchmarking it against an Exhaustive Search approach. Results show that AS method gives satisfactory optimal solutions reducing the computation cost for scenarios having several hundred of PEVs,

Index Terms-Ant System, plug-in electric vehicles, current unbalance, stochastic combinatorial optimization
\end{abstract}

\section{INTRODUCTION}

Voltage and current unbalances will be significantly affected by a high penetration of PEVs as single-phase loads of the residential network. According to [1], for different scenarios of a low voltage network, an increasing number of PEVs in vehicle-to-grid (V2G) scenario would increase by more than $20 \%$, the probability of exceeding maximum standard ratings of the voltage unbalance factor (VUF). Since the current unbalance is one of the causes of voltage unbalance [2], the current unbalance, generated by the variable number of PEVs connecting and disconnecting at random times, is an important issue to be addressed.

Current and voltage unbalances, similar to other power-quality issues, are regulated by the distribution system manager by sending operators to execute maintenance on medium-voltage to low-voltage (MV/LV) transformers and distribution lines. In the context of the smartgrids, this procedure could be part of a portfolio of support services where active and intelligent loads, such as PEVs, could participate. Examples of such portfolio of services PEVs would be able to provide are ancillary services [3]-[6] and smart charging strategies to reduce PEVs's impact on the MV/LV transformer [7], [8].

Several papers have studied this subject. In [9], authors propose a solution for voltage unbalance consisting in a static transfer switch installed on every LV load where it is controlled by a rule-based algorithm that commutes loads from high loaded lines towards low loaded ones. In [10], current unbalance factor is reduced by controlling rooftop PVs as varying capacitors. Concerning PEVs, in [11], a rule-based method is proposed in order to reduce the current unbalance factor by controlling only reactive power of a charging station without interfering with the active power.

In this paper, a new strategy based on combinatorial optimization is proposed in order to minimize the current unbalance factor by controlling the connection and disconnection of PEVs available in a LV residential network. PEVs are considered binary (ON/OFF) controllable loads charging at a constant rate. The problem, as it will be shown, has a combinatorial nature whose complexity grows exponentially with the number of controllable PEVs. For combinatorial problems the optimal solution exists and the complexity depends on the time it would take to find the optimum by enumerating and comparing all possible solutions.

The combinatorial optimization method chosen is the Ant system (AS). AS is a computation paradigm based on stochastic combinatorial optimization [12]. This method is part of the family of bio-inspired optimization called Ant Colony Optimization (ACO) [13]. The objective is to find an optimal solution to a complex problem, or the closest acceptable solution by "randomly" searching through an space of solutions without enumerating all of them. In addition, Exhaustive Search (ES) method is used to benchmark the AS method. ES or brut-force search, is the method that enumerates all possible solutions of an optimization problem in order to rank them for after, finally, choosing the best. ACO has been used in different power system optimization problems [14], [15].

This paper is organized as follows: In section II, the current unbalance factor problem is formulated. An Ant system framework is presented as well as its adaptation to the optimization problem in section III. In section IV, the simulation environment focusing in the comparison of the AS and the ES method is described. In section V, results are analyzed. The paper ends with some conclusions and future work. 


\section{PROBlem Formulation}

\section{A. PEV charging stations}

The charging stations considered, is a level two single-phase installation that provides $3 \mathrm{~kW}$, or a charging current, $\mathbf{I}_{C h}$, equal to $13 A$, to the PEV charger. Let's assume that the charging stations receive orders to connect or disconnect the PEV available from the distribution system operator through a perfect communication channel.

\section{B. Current Unbalance Factor}

Fig.1 illustrates a common scenario of a LV network feeding a common-connection-point $(\mathrm{CCP})$ that gathers residential loads including PEVs. It is a three-phase three-wire system with single-phase phase-to-neutral loads with $\mathbf{I}_{a}, \mathbf{I}_{b}$ and $\mathbf{I}_{c}$ as the line currents. Each phase-to-neutral voltages is represented by $\mathbf{V}_{a N}, \mathbf{V}_{b N}$ and $\mathbf{V}_{c N}$ respectively. According to the standard IEEE 1159-2009 [16], the samples of the current unbalance factor (CUF) in a three-phase CCP has to be less $30 \%$ in steady state. The CUF is defined by:

$$
\mathrm{CUF}=\left|\frac{\mathbf{I}_{2}}{\mathbf{I}_{1}}\right|
$$

With $\mathbf{I}_{2}$ and $\mathbf{I}_{1}$ represent the negative and the positive symmetrical sequence currents respectively, both calculated using the line currents at a CCP. A $C U F$ measure is an average over 10 minutes of the CUF sampled every 30 seconds.

Fortescue symmetrical sequence currents are defined as follows:

$$
\left(\begin{array}{l}
\mathbf{I}_{1} \\
\mathbf{I}_{2} \\
\mathbf{I}_{0}
\end{array}\right)=\left(\frac{1}{3}\right) \mathbf{F}^{-1}\left(\begin{array}{l}
\mathbf{I}_{a} \\
\mathbf{I}_{b} \\
\mathbf{I}_{c}
\end{array}\right)
$$

where $F=\left(\begin{array}{ccc}1 & 1 & 1 \\ \mathbf{a}^{2} & \mathbf{a} & 1 \\ \mathbf{a} & \mathbf{a}^{2} & 1\end{array}\right)$ with $\mathbf{a}=e^{2 \pi i / 3}$.

Each line current is the summation of the currents of the loads connected to it. As a result eq. (2) can be rewritten in a compact form (eq.(3)), where $N P E V^{a}, N P E V^{b}$ and $N P E V^{c}$ are the number of PEVs available at the residencies connected either to phase $a$ or $b$ or $c . \mathbf{I}_{P E V j}^{a}, \mathbf{I}_{P E V j}^{b}$ and

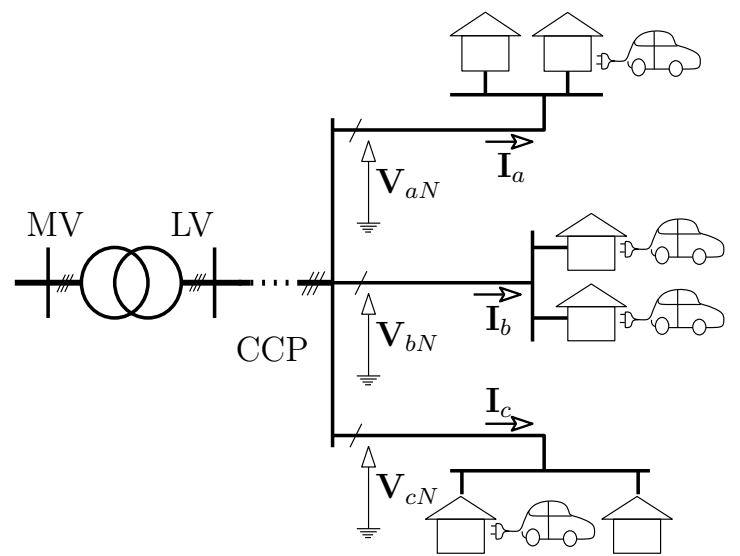

Fig. 1: Common connection point (CCP) in a LV network
$\mathbf{I}_{P E V j}^{c}$ are the currents of the $j$-th PEV connected either to phase $a$ or $b$ or $c . N H^{a}, N H^{b}$ and $N H^{c}$ is the number of residences connected either to phase $a$ or $b$ or $c$. Finally, $\mathbf{I}_{H k}^{a}, \mathbf{I}_{H k}^{b}$ and $\mathbf{I}_{H k}^{c}$ are the currents of the $k$-th householder connected either to phase $a$ or $b$ or $c$.

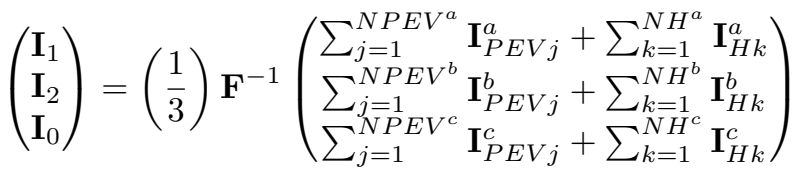

In this paper, PEVs are considered as binary loads loads (ON/OFF). Assuming that, in total, $N$ PEVS are connected to the CCP and each one of the charging stations have the same charging current magnitude, $\mathbf{I}_{C h}$. Eq.(4) shows the symmetrical sequences as a function of the PEVs currents. Negative and positive sequence currents in eq.(4) will be used to modify the CUF as a function of the connection and disconnection of the PEVs.

$$
\begin{aligned}
\left(\begin{array}{l}
\mathbf{I}_{1} \\
\mathbf{I}_{2} \\
\mathbf{I}_{0}
\end{array}\right) & =\left(\frac{1}{3}\right) \cdot \mathbf{F}^{-1} \\
& \cdot\left(\begin{array}{c}
N P E V^{a} \\
\sum_{l=1}^{N} \mathbf{I}_{C h} \cdot d_{l}+\sum_{k=1}^{N H^{a}} \mathbf{I}_{H k}^{a} \\
N P E V^{b}+N P E V^{a} \\
\sum_{l=N P E V^{a}+1}^{N} \mathbf{I}_{C h} \cdot d_{l}+\sum_{k=1}^{N H^{b}} \mathbf{I}_{H k}^{b} \\
\sum_{l=N P E V^{b}+N P E V^{a}+1}^{N H^{c}}
\end{array}\right.
\end{aligned}
$$

where $d_{l}$ is the control signal of the $l$-th PEV. Thus, a solution that minimize the CUF at the CCP is given by :

$$
\begin{aligned}
\mathbf{d}= & {\left[d_{1}, d_{2}, \ldots, d_{l}, \ldots, d_{N}\right] } \\
& d_{l}=\left\{\begin{array}{rr}
0 & \mathrm{PEV}_{l} \text { disconnected } \\
1 & \mathrm{PEV}_{l} \text { connected }
\end{array}\right. \\
& \forall l=1, \ldots, N
\end{aligned}
$$

\section{ANT SYSTEM FRAMEWORK}

Ant System (AS) algorithms imitates the behavior of real ants. It is well known that real ants are able to find the shortest path between food sources and the nest without using visual support. Real ants are also capable of adapting to changes in the environment, such as new obstacles on shortest path. Ants cooperate to find the shortest path, by communicating through a medium called "pheromone". The pheromone is deposited by the ants as they move through paths between different locations and, at the same time, ants keep track of the pheromone already left on the path. Trials richer in pheromone will become preferred paths. Finally after many itineraries, the path that has been walked over the most will be the shortest path.

Fig. 2 is a representation of real ants behavior. In Fig.2(a), ants move from the food source, located at point A, towards the nest located at point B. Once an obstacle blocks the path, like in Fig.2(b), the ants are not able to follow the same trial. At locations C and D, ants face the same probability to 


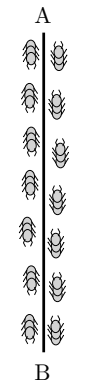

(a)

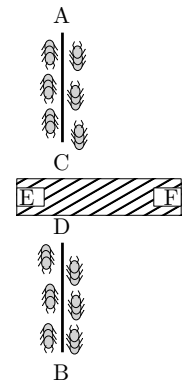

(b)

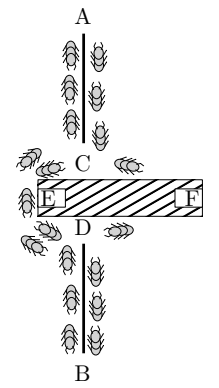

(c)
Fig. 2: An exemple of real ants behavior

either take the long path (C-F-D) or the short path (C-E-D). Nevertheless, after several travels the shortest path will collect pheromone faster than the longest path and as it is illustrated in Fig.2(c), more ants will follow this trial leaving even more pheromone. Thanks to this positive feedback, after a few itineraries, all ants will choose the shortest path. This behavior is the fundamental paradigm of the AS algorithms. The main characteristics of this framework are positive feedback, for rapid discovery of solutions, distributed computation, to avoid premature convergence and greedy heuristic helping to find acceptable solutions at the first stages of the algorithm.

\section{A. Search Space Representation}

Fig.3 illustrates the search space suitable to apply the AS method to the CUF minimization problem. The number of stages is equal to the number of phases. The number of locations or states per stage is equal to the number of PEVs connected among the PEVs available. The number of PEVs connected to each phase, $C_{P E V a}, C_{P E V b}$ and $C_{P E V c}$, is given by eq.(6).

$$
\begin{aligned}
C(\mathbf{d})_{P E V a} & =\sum_{l=1}^{N P E V^{a}} d_{l} \\
C(\mathbf{d})_{P E V b} & =\sum_{l=N P E V^{a}+1}^{N P E V^{b}+N P E V^{a}} d_{l} \\
C(\mathbf{d})_{P E V c} & =\sum_{l=N P E V^{b}+N P E V^{a}+1}^{N P E V^{c}+N P E V^{b}+N P E V^{a}} d_{l}
\end{aligned}
$$

\section{B. State Transition Rule}

The state transition rule for AS algorithmes, called a random-proportional rule, is given in eq.(7), which gives the probability of with which ant $e$ in state $i$, located at the stage $x$, chooses to move to state $j$, located at the stage $y$.

$$
p_{e}^{x y}(i, j)=\left\{\begin{array}{lr}
\frac{\left[\tau^{x y}(i, j)\right]\left[\eta^{x y}(i, j)\right]^{\beta}}{\sum_{m \in J_{e}(i)}\left[\tau^{x y}(i, m)\right]\left[\eta^{x y}(i, m)\right]^{\beta}}, & \text { if } j \in J_{e}(i) \\
0, & \text { Otherwise }
\end{array}\right.
$$

In eq.(7), $\tau$ is the pheromone deposited on the edge between the states $i$ and $j, \eta$ is the inverse of the length of the edge;

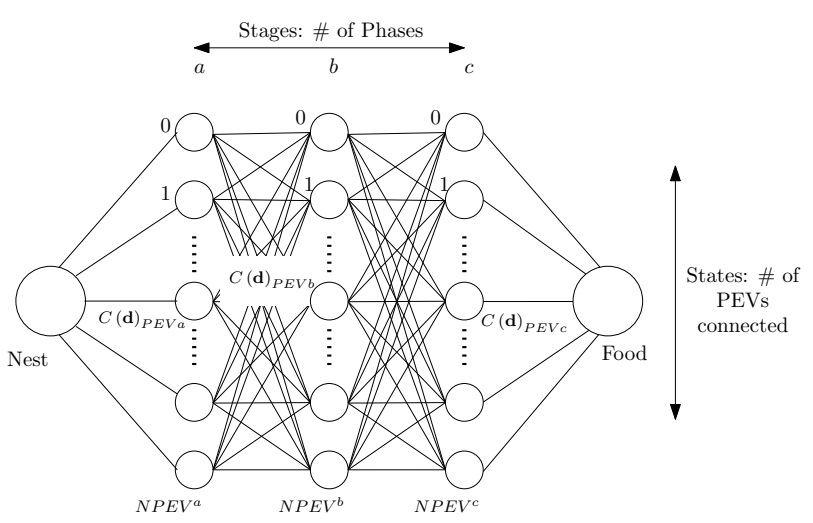

Fig. 3: Search Space representation

$J_{e}(i)$ is the set of states that remain to be visited by ant $e$ located in $i$, and finally, $\beta$ is the parameter which determines the relative importance of pheromone versus distance. Eq.(7) indicates that the state transition rule favors transitions toward states connected by shorter edges and with greater amount of pheromone.

\section{Global Updating Rule}

Once all ants have built their tours, the pheromone is updated on all edges according to eq.(8). Pheromone updating is intended to allocate a greater amount of pheromone to shorter tours. A tour is the trial taken by an ant going through all the stages.

$$
\begin{aligned}
& \tau^{x y}(i, j) \leftarrow(1-\alpha) \cdot \tau^{x y}(i, j)+\sum_{e=1}^{N_{\text {ants }}} \Delta \tau_{e}^{x y}(i, j) \\
& \Delta \tau_{e}^{x y}(i, j)=\left\{\begin{array}{lr}
\frac{1}{L_{e}}, & \text { if }(i, j) \in \text { tour done by ant } e \\
0, & \text { Otherwise }
\end{array}\right.
\end{aligned}
$$

In eq.(8), $\alpha \in[0,1]$ is the pheromone decay, $L_{e}$ is the length of the tour performed by the ant $e$ and $N_{\text {ants }}$ is the total number of ants.

\section{AS method}

The objective of the AS method is to minimize the CUF by selecting the amount of PEVs to connect per phase among those available. Therefore, the fitness function is the CUF assessed by using the symmetrical sequences from eq.(4) and the optimal solution will be given by eq.(6), or in other words by the set $\mathbf{d}$. The optimization problem is synthesized as follows eq.(9).

$$
\min _{\mathbf{I}_{1}, \mathbf{I}_{2} \text { eq.(4) }} \mathrm{CUF}=\left|\frac{\mathbf{I}_{2}}{\mathbf{I}_{1}}\right|
$$

The computational procedure to apply the AS method is illustrated on Fig.4 and it is detailed as follows:

Step 1 Initialization: To Initialize the procedure, fitness function parameters, AS procedure parameters and the search space must be defined. Fitness function has been defined in eq.(4), therefore its parameters 


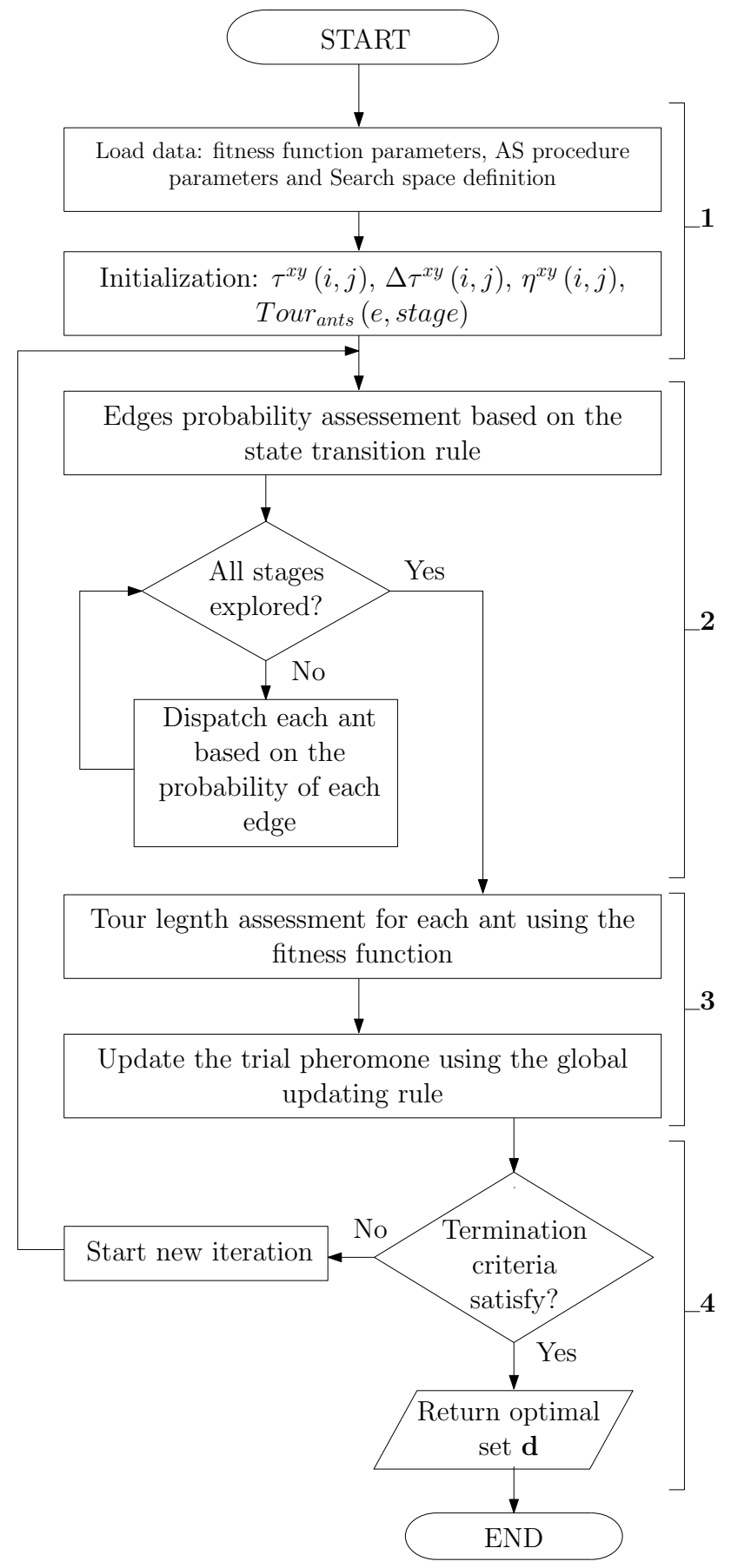

Fig. 4: AS method algorithm

are the number of PEVs available in each one of the phases $\left(N P E V^{a}, N P E V^{b}\right.$ and $\left.N P E V^{c}\right)$, the householders currents $\left(I_{H k}^{a}, \mathbf{I}_{H k}^{b}\right.$ and $\mathbf{I}_{H k}^{c}$ for all $k$ connected either to phase $a, b$ or $c$ ) and the charging current. The AS parameters $(\alpha, \beta, \rho)$ are determined empirically prior. Furthermore, stages of the search space are equal to the number of phases and states are defined according to the number of PEVs available in each one of the phases. Matrices $\tau^{x y}(i, j)$,
$\Delta \tau_{e}^{x y}(i, j), \eta^{x y}(i, j)$ and $\operatorname{Tour}_{\text {ants }}(e$, stage $)$ are initialized. Tour ants $(e$, stage $)$ is the matrix containing the tours for each ant, or in other words, the states traveled by each ant through all the stages.

Step 2 Tours building: The state transition rule is assessed using eq.(7), and next ants are dispatched based on the from one stage to another based on the probability of the edges available. This process is repeated for each one of the ants until going through all the stages.

Step 3 Pheromone updating: The length of the tour completed by each ant is assessed and the pheromone is updated using the global updating rule (eq.(8))

Step 4 Termination criteria: The lengths of the tours of each ant are compared and the shortest path is selected. This value is minimum of the fitness function (CUF assessed with eq.(4)) for the current iteration. The states belonging to the shorthest tour define the number of PEVs connected to each phase according to eq.(6) $\left(C_{P E V a}, C_{P E V b}\right.$ and $\left.C_{P E V c}\right)$ and, as a result, a set $\mathbf{d}$ is calculated. If the minimum is stable or the maximum number of iterations have been reached, the set $\mathbf{d}$ of the current iteration is the optimal set minimizing the fitness function, otherwise a new iteration is executed starting from step 2.

\section{COMparison with Exhaustive Search}

The performance of AS method to solve the CUF minimization problem is compared with that of Exhaustive Search (ES) method. ES method has been chosen as benchmarking because it is a method that provides the global optimal solution to any combinatorial problem at the expenses of costly computation time. So compared to it, it is possible to characterized the AS method proposed in terms of proximity to the optimal solution and reduced computation time.

To compare these two methods, initial conditions for the optimization problem (eq.(9)) are randomly generated based on random selection of the fitness function parameters inside the intervals in TABLE I. In total, 1500 CUF initial conditions were minimized using both methods ES and AS. The proposed methods have been implemented in MATLAB and run on an Intel Core i5-42000, $2.29 \mathrm{GHz}$ personal computer.

TABLE I: Fitness function parameter intervals

\begin{tabular}{|c|c|}
\hline Parameter & Interval \\
\hline$N P E V^{a, b \text { or } ~}$ & {$[0,400]$} \\
\hline$N H^{a, b \text { or c }}$ & $0.7 * N P E V^{a, \text { borc }}$ \\
\hline $\mathbf{I}_{H k}^{a, b \text { or c }}$ & {$[0,20 A]$} \\
\hline $\cos (\varphi)$ householders & {$[0,0.2]$} \\
\hline$I_{C h}$ & $13 \mathrm{~A}$ \\
\hline
\end{tabular}




\section{RESUlts AND Discussion}

The data from the simulation is illustrated on Fig.5 in descending order of the ES method data. Initial conditions are represented in blue, AS solutions are represented in red and ES solutions are represented in black. It is possible to notice that both results minimize the initial conditions randomly generated. Furthermore, as it was expected, ES method provides the optimal solutions and it works to compare the quality of the AS method solutions for the same initial conditions.

\section{A. Computation time}

In terms of computation time, Fig. 6 plots the computation time each method needs find the optimal solution starting a initial condition as a function of the number of PEVs available in each trial. The dashed line emphasized the trials in which the computation time of both methods is on the same range; these are the trials between 40 PEVs et 140 PEVs with computation times between $0.07 s$ and $0.7 s$. For trials having less than $40 \mathrm{PEVs}$, the ES method has lower computation time than the AS method; as a result, the difference between the computation time is approximately $0.0358 \mathrm{~s}$, for the trial with the least amount of PEVs available (12 PEVs). For the trials having more than 140 PEVs, AS method has lower computation time; then for the trial with the biggest number of PEVs available ( $365 \mathrm{PEVs}$ ), the difference between the computation times is approximately $14.1 \mathrm{~s}$. To conclude, it is convenient to use the AS method proposed when the number of PEVs available is larger than roughly 140 PEVs.

\section{B. Comparison of optimal solutions}

The ratio of the optimum value, for each method, to the CUF initial condition is illustrated in Fig.7 and on Fig.8. For both methods and for most of the trials, the CUF is reduced with respect to its initial condition. Let be assume that the number of optimal values found by the methods under a ratio of 0.1 (red dashed line in Fig.7 and in Fig.8) is a method performance indicator. Regarding the ES method, the CUF is

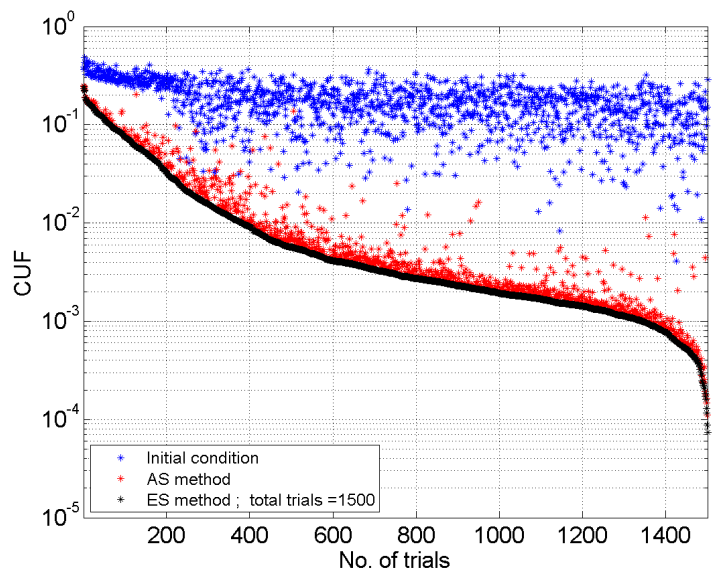

Fig. 5: Initial conditions, ES and AS data in descending order

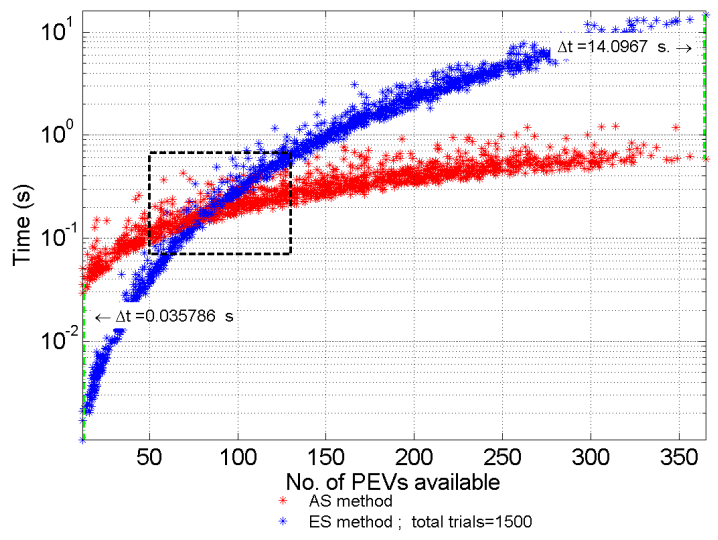

Fig. 6: Computation time vs. the number of PEVs available

minimized more than 10 times in more than $79 \%$ of the trials. Similarly, regarding the AS method, the CUF is minimized more than 10 times in more than $75 \%$ of the trials. Therefore, AS method performance indicator is $4 \%$ below that of ES method. Considering computing time characteristics described in the previous section, regarding the ES method, the CUF is minimized more than 10 times in more than $42.8 \%$ of the trials with more than 140 PEVs. Likewise, regarding the AS method, the CUF is minimized more than 10 times in more than $42.07 \%$ of the trials with more than 140 PEVs. Consequently, the performance of the AS method increases with the number of PHEVs. On Fig.9, the error between the ratios of the two methods is presented. It is confirmed that the optimal solutions found by the AS method are closer to the global optimal solutions proportionally with higher number of PEVs available.

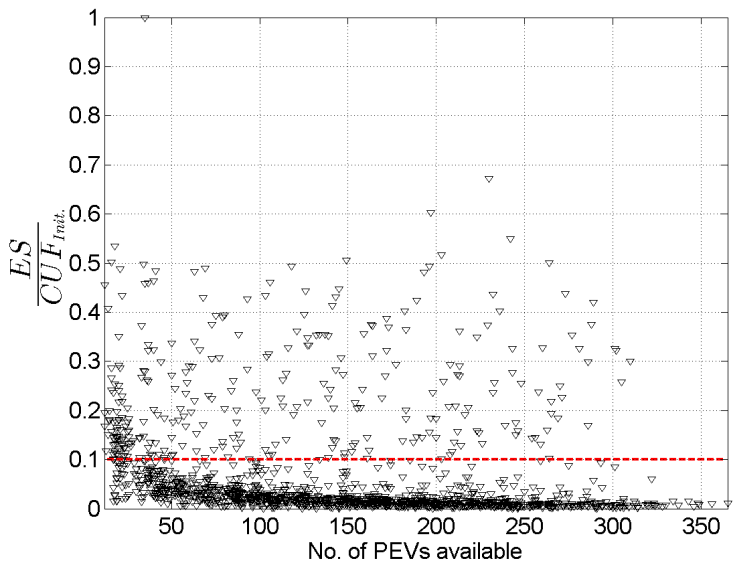

Fig. 7: Ratio of ES solutions to CUF initial conditions $\left(\mathrm{CUF}_{\text {Init. }}\right)$ vs. the number of PEVs available. The red line indicates a ratio of 0.1 


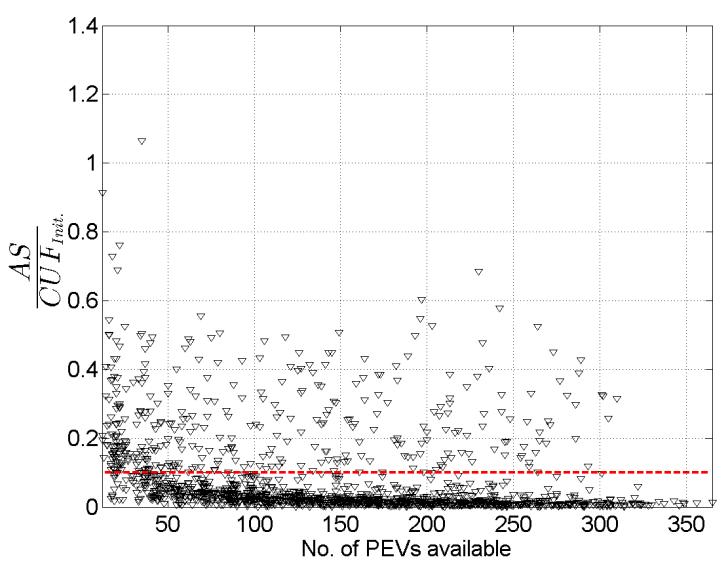

Fig. 8: Ratio of AS solutions to CUF initial conditions $\left(C U F_{\text {Init. }}\right)$ vs. the number of PEVs available. The red line indicates a ratio of 0.1

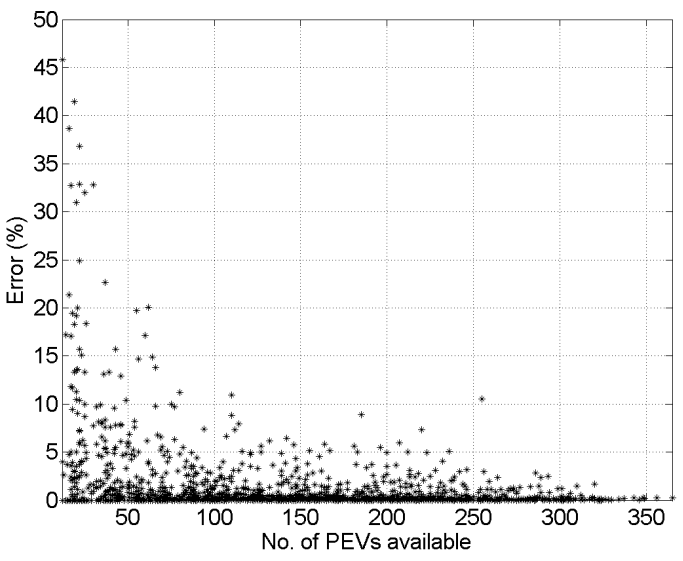

Fig. 9: Error between ES and AS ratios to the $C U F_{\text {init. }}$ vs. the number of PEVs available

\section{CONCLUSION}

Ant System method was adapted in this paper in order to minimize the current unbalance factor formulated as a combinatorial problem, this is PEVs are binary (ON/OFF) controllable loads and each one is an optimization variable. A simulation environment was implemented in order to compare the AS method against the ES method. Results have shown that when the number of PEVs available at a LV network, AS method finds suitable optimal solutions at a low computational cost.

As further work, CUF have to be addressed as a continuous optimization problem in which the power from the PEVs could be modified under constraints. Additionally, infrastructure and usage constraints, such as a complete state-of-charge of batteries at departure time, must be considered. Finally the profit for PEVs as well as for the grid have to be assessed in order to quantify the benefit of current unbalance minimization for PEV users.

\section{ACKNOWLEDGMENT}

This work was supported by the Smart Energy project and the ANR PARADISE Project.

\section{REFERENCES}

[1] F. Shahnia, A. Ghosh, G. Ledwich, and F. Zare, "Predicting voltage unbalance impacts of plug-in electric vehicles penetration in residential low-voltage distribution networks," Electric Power Components and Systems, vol. 41, no. 16, pp. 1594-1616, 2013.

[2] U. Jayatunga, S. Perera, and P. Ciufo, "Voltage unbalance emission assessment in radial power systems," Power Delivery, IEEE Transactions on, vol. 27, no. 3, pp. 1653-1661, July 2012.

[3] E. Sortomme and M. El-Sharkawi," Optimal scheduling of vehicle-togrid energy and ancillary services," Smart Grid, IEEE Transactions on, vol. 3, no. 1, pp. 351-359, March 2012.

[4] S.-L. Andersson, A. Elofsson, M. Galus, L. Gransson, S. Karlsson, F. Johnsson, and G. Andersson, "Plug-in hybrid electric vehicles as regulating power providers: Case studies of sweden and germany," Energy Policy, vol. 38, no. 6, pp. 2751 - 2762, 2010, the Role of Trust in Managing Uncertainties in the Transition to a Sustainable Energy Economy, Special Section with Regular Papers.

[5] H. K. Nguyen and J. B. Song, "Optimal charging and discharging for multiple phevs with demand side management in vehicle-to-building," Communications and Networks, Journal of, vol. 14, no. 6, pp. 662-671, Dec 2012.

[6] W. Kempton and J. Tomic, "Vehicle-to-grid power fundamentals: Calculating capacity and net revenue," Journal of Power Sources, vol. 144, no. 1, pp. $268-279,2005$.

[7] H. Turker, S. Bacha, D. Chatroux, and A. Hably, "Low-voltage transformer loss-of-life assessments for a high penetration of plug-in hybrid electric vehicles (phevs)," Power Delivery, IEEE Transactions on, vol. 27, no. 3, pp. 1323-1331, July 2012.

[8] H. Turker, A. Hably, S. Bacha, and D. Chatroux, "Rule based algorithm for plug-in hybrid electric vehicles (phevs) integration in residential electric grid areas," in Innovative Smart Grid Technologies (ISGT), 2012 IEEE PES, Jan 2012, pp. 1-7.

[9] F. Shahnia, P. Wolfs, and A. Ghosh, "Voltage unbalance reduction in low voltage feeders by dynamic switching of residential customers among three phases," in Power and Energy Society General Meeting (PES), 2013 IEEE, July 2013, pp. 1-5.

[10] F. Shahnia, A. Ghosh, G. Ledwich, and F. Zare, "An approach for current balancing in distribution networks with rooftop pvs," in Power and Energy Society General Meeting, 2012 IEEE, July 2012, pp. 1-6.

[11] J. Fernandez, S. Bacha, D. Riu, H. Turker, and M. Paupert, "Current unbalance reduction in three-phase systems using single phase phev chargers," in Industrial Technology (ICIT), 2013 IEEE International Conference on, Feb 2013, pp. 1940-1945.

[12] M. Dorigo, V. Maniezzo, and A. Colorni, "Ant system: optimization by a colony of cooperating agents," Systems, Man, and Cybernetics, Part B: Cybernetics, IEEE Transactions on, vol. 26, no. 1, pp. 29-41, Feb 1996.

[13] M. Dorigo and T. Stutzle, "Ant colony optimization: overview and recent advances," in Handbook of metaheuristics. Springer, 2010, pp. 227263.

[14] Y.-K. Wu, C.-Y. Lee, L.-C. Liu, and S.-H. Tsai, "Study of reconfiguration for the distribution system with distributed generators," Power Delivery, IEEE Transactions on, vol. 25, no. 3, pp. 1678-1685, July 2010.

[15] D. Niu, Y. Wang, and D. D. Wu, "Power load forecasting using support vector machine and ant colony optimization," Expert Systems with Applications, vol. 37, no. 3, pp. $2531-2539,2010$.

[16] "Ieee recommended practice for monitoring electric power quality," IEEE Std 1159-2009 (Revision of IEEE Std 1159-1995), pp. c1-81, June 2009. 